\title{
Rural development and sustainable innovation. How Systemic Design approach can contribute to the growth of marginal regions
}

\author{
Bicocca, Miriam \\ Department of Architecture and Design, Politecnico di Torino, Italy. miriam.bicocca@polito.it
}

\begin{abstract}
The objective of this project is to reach sustainable development in rural areas through Design Aapproaches. We intend here, as "sustainable", that matches the three dimensions of sustainability, that works for people, planet and profit - a 'triple P' challenge. Sustainable development consists of goals, strategies, and processes that together provide more socially, economically and ecologically alternative tracks to conventional development, offering improved livelihoods to the poor in ways that promote both their empowerment and the conservation or improvement of key natural resources so that the basis of productive activities can be maintained into the future (Lele 1991; Pretty 1998). The topic of rural development is very relevant becouse of the quantity of people, very often poor or extremely poor people, living in rural territories. More than 3 billion people live in rural areas. Design rarely deals with rural development and with the definition of a system that can facilitate the growth and the development of the territory. If it does, design usually focuses on products or services.
\end{abstract}

The most important futures, which globally all rural areas share in common, are remoteness and isolation. Many development specialists and rural sociologists argue that small structure and cooperation are important strengths that contribute to ethic and social identity. The central role that play territorial context and relationships in the Systemic Design Approach (SDA) makes it a very effective approach to support and encourage rural development in a sustainable way. Applying the SDA, it is possible to manage local resources and local products in a way that allows the economic strengthening of the farmers and communities that live in the territory.

The Systemic Design team of the Deparment of Architecture and Design (DAD) of Politecnico di Torino has been engaged for years into the develop of the approach of Systemic Design that can be summed up by five basic principles (Bistagnino 2011: 19):

Output > Input: the output (waste) of a system becomes the input (resource) for another one

Relationships that generate the system, each one contributes to the system

Auto-generation systems sustain themselves by reproducing automatically, thus allow them to define their own paths of action and jointly co-evolve

Act locally: context is fundamental because it values local resources (humans, cultures and materials) and it helps to modify local problems in new opportunities. 
Rural development and sustainable innovation. How Systemic Design approach can contribute to the growth of marginal regions.

Man at the centre of the project: Man is connected to own environmental, social, cultural and ethic context.

It is essential to start from the current state of the art, that allows to define strengths and weaknesses, before to design the system, made of flows between actors.

Keywords: systemic design, rural development, inclusive, cooperation

\section{Introduction}

The purpose of this work is to understand how to reach rural development in a sustainable way (that works for people, planet and profit - a 'triple $\mathrm{P}$ ' challenge) in marginal and complex areas, in particular, in rural areas. Sustainable development consists of goals, strategies, and processes that together provide more socially, economically and ecologically alternative tracks to conventional development, offering improved livelihoods to the poor in ways that promote both their empowerment and the conservation or improvement of key natural resources so that the basis of productive activities can be maintained into the future (Lele 1991; Pretty 1998). The work done has the objective to encourage social innovation processes for the improvement of the quality of life and the economic wellbeing of people in marginal areas. Achieving sustainability, in environmental, economic and social terms, on small rural areas is no longer a possibility but an imperative. Rural areas, all over the world, are fragile environment aggravated by stagnant economies, high unemployment, persistent poverty, deteriorated social well being, lower earnings and diminished health care. Social changes, such as large-scale migration, and climate change have major consequences for small-scale farmers in the developing rural areas of the world. Currently over $50 \%$ of the world population still directly depends on rural livelihoods that are highly vulnerable to climate change (McIntyre et al., 2009). Rural development is a very relevant topic because of the quantity of people that lives in this situation. More than 3 billion people live in rural areas and 1.4 billion people are extremely poor. Identification of innovative processes useful for the development of small-scale farmers, therefore, is crucial. Increased infrastructure, market access and information, and creative financial solutions are necessary for sustainable increases in productivity. To reduce poverty in rural areas is necessary to invest in agricultural and rural development.

The most important case study of the research work takes place in Mexico, State of Guerrero, Ahuacuotzingo. This region was chosen because of its particular features related to food, both the production and the consumption. Take action on these aspects means managing environmental, social, economic and health consequences. Approximately one quarter of Mexico's 100 million people live in rural areas, and depend primarily on agriculture. Farming is important for land use and for the management of natural resources. Thus farmers are fundamental social, cultural and economic actors in rural areas. Important are also the agro-food networks that are generated. Since the main part of the research is the project with the Cooperative Ahuehuetla in Mexico, we need to consider that agriculture in Mexico is not only a fundamental economic activity of the rural population involving about $37 \%$ of the total population, but has also deep social significance and cultural meaning. 
The most important futures, which globally all rural areas share in common, are remoteness and isolation. Many development specialists and rural sociologists argue that small structure and cooperation are important strengths that contribute to ethic and social identity. Support and facilitate positive change for rural development must include the participation of small communities. Local people need to be encouraged to think about their futures and to put into practice their ideas, founded on their culture and traditions. Therefore, the goal of this research is to lean a process based on capacities and ability of local people.

The central role that play local resources and relationships in the Systemic Design Approach (SDA) makes it a very effective approach to support and encourage rural development in a sustainable way. Applying the SDA, it is possible to manage local resources and local products in a way that allows the economic strengthening of the farmers and communities that live in the territory.

Since farming is a mainstay of most rural economies, the research aims to promote economic diversification combining traditional agricultural skills and new technical and technological know-how. This mainly because rural areas are characterized by a strong and evident contrasting perception of the traditional and local culture. On one side a very strong sense of belonging to the territory, the local culture and the tradition. On the other side the perception, shared by the majority of the population, of what is linked to tradition and indigenous culture as poor, worthless. The answers to the problems of these complex territories, cannot be found only looking to the past. Solutions should be promoters of innovation, with the attention and sensitivity to the local culture. This is the reason why an important section of this work is focused on technologies.

\section{State of the Art}

\subsection{Rural Development (RD) and Social Innovation (SI)}

Since the most important objective and goal of the research is to generate rural development we need to define what rural development is, what it really means and what practical consequences might have on the territory and local communities. There is no universally accepted definition of rural development. It is the result of various physical, technological, economic, socio-cultural and institutional factors and it represents an intersection of agricultural, social, behavioural and management of sciences. Rural development can be defined as, helping rural people set the priorities in their own communities by providing the local capacity. According to Robert Chambers, rural development is a strategy to enable a specific group of people, poor rural women and men, to gain for themselves, and their children more of what they want and need. We can define rural development as a Process leading to sustainable improvement in the quality of life of rural people, specially the poor.

\subsection{Social innovation}

In public discussions and in policy, innovation is still almost exclusively treated and perceived as economic innovation focusing on technical efficiency as well as the commercialisation of science and technology (Adams and Hess 2008, pag 5).

The traditional technological or economic innovation is usually the result of internal research and development conducted in a company or institution that leads to the market introduction of a new product, service or technology. Social innovation, in contrast with technological and economic innovation is not teleological and may not necessarily have an economic impetus. 
During this research we discuss social innovation from a rural development perspective. The classic formulas of process and product innovation are part of an economic paradigm, which often represents, itself, the cause of certain problems, especially for the environment. This is also the reason why, the topic of innovation, today, is differently declined, in his social meaning. Social innovation processes work especially where market fails and where public policies do not offer adequate solutions to the challenges. This especially where governance structures are weak to find solutions for complex problems and hesitate to generate answers to the needs in local systems. Social innovation processes are capable of mobilizing, openly and continuously, a large number of actors active in the local system searching useful solutions (Murray et all, 2010).

Brunori et al. (2008) write about the evolution of innovation studies in agriculture, showing the progressive shift from a 'linear' or so called 'exogenous' conception of innovation to a 'systemic' or 'endogenous' approach, defining innovation as a learning process. Brunori asserts that innovation occurs when the network of production changes its way of doing things. In this sense innovation is related to the resulting pattern of interaction between people, tools, natural resources. With this new vision, learning becomes the core of innovation processes.

Innovation thus is not only technological innovation. Is more related to a successful change in production, consumption and distribution systems. Indeed comprehend new practices, artefacts and/or combinations able to generate a process of production, a network, the integration of two different activities.

What I find very interesting and useful for this research is well described by Van der Ploeg et al. (2008). Social innovation must be strongly connected with locality and contextual knowledge. This means that innovation is linked to a specific context, many times to a specific region.

\section{Description of the research work}

The research work consists of several parts. The structure chosen to describe the research path does not follow the chronological order. The search path has been marked by several revisions and changes in direction.

The work is mainly structured in 3 parts. The first one is the analysis and the definition of the state of the art. The second one is the Systemic Design Project of flows and relationships in collaboration with the Cooperative Ahuehuetla of Ahuacuotzingo, State of Guerrero, Mexico. The last part is the implementation, or definition of the steps necessary to put this project into effect, and the framework that outcomes from the research.

\subsection{Ahuacuotzingo, State of Guerrero, Mexico}

The territory of the State of Guerrero, and in particular Ahuacuotzingo, has been investigated and analysed from several perspectives.

Named for Vicente Guerrero, a leader in Mexico's wars for independence, the region became a state in 1849. Guerrero is divided into local governmental units called municipios (municipalities), each of which is headquartered in a prominent city, town, or village. Much of the state's population consists of impoverished Indians and mestizos, a significant minority of whom speak an indigenous language as their primary language; more than two-fifths of the people live in rural areas. Considering the standard economic measures, it is easy to notice that Guerrero consistently ranks among Mexico's most impoverished states. The transportation infrastructure is poorly developed and maintained. The rural population lives dispersed among scattered and often very isolated villages; in 2010 just over fifty-eight 
per cent of the state's population was spread among more than seven thousand communities with fewer than 2,500 residents.

For a substantial majority of the rural population, the subsistence agriculture with supplemental commodity production or seasonal wage employment remains a way of life.

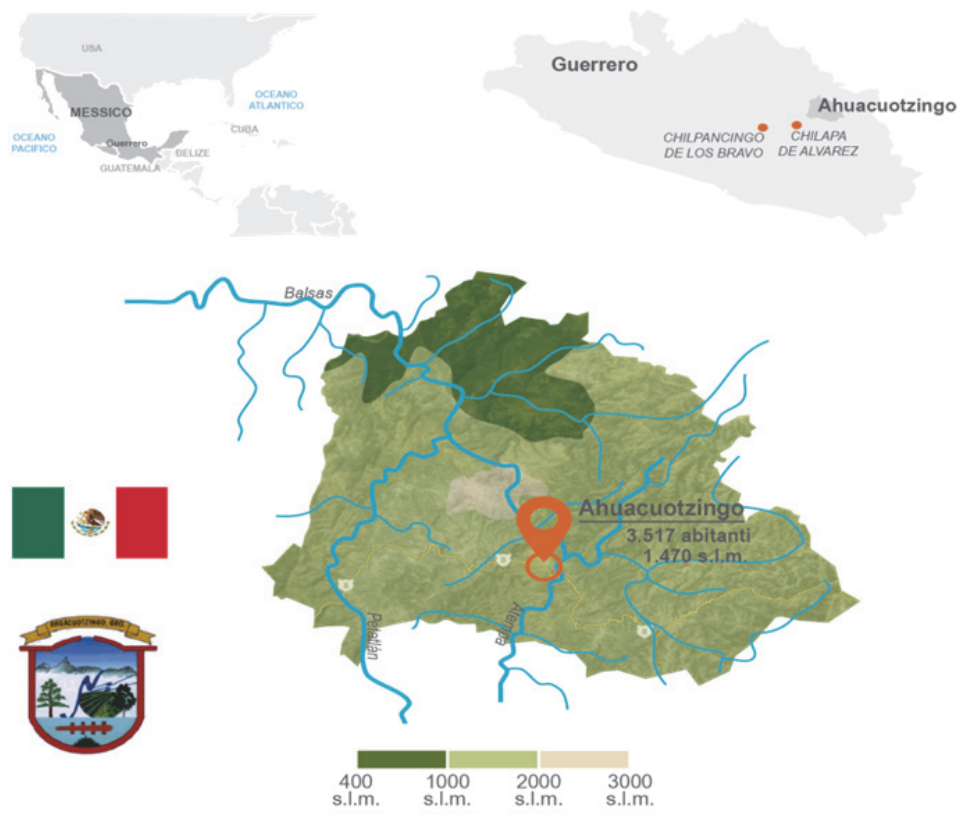

Fig. 1 Map of Ahuacuotzingo, State of Guerrero, Mexico

One of the 81 municipalities of the State of Guerrero is Ahuacuotzingo. Approximately $60 \mathrm{~km}$ from the capital Chilpancingo, its territorial extension is of $388,4 \mathrm{~km}^{2}$ and the population mainly dedicates to primary Sector. The subsistence agriculture is the most important activity for people of Ahuacuotzingo. Subsistence agriculture is self-sufficiency farming in which the farmers focus on growing enough food to feed themselves and their families. Tony Waters writes: "Subsistence peasants are people who grow what they eat, build their own houses, and live without regularly making purchases in the marketplace." However, despite the primacy of self-sufficiency in subsistence farming, today most subsistence farmers also participate in trade to some degree, though usually it is for goods that are not necessary for survival, and may include sugar, iron roofing sheets, bicycles, used clothing, and so forth.

As many rural areas are, the territory of Ahuacuotzingo is characterized by low population and enterprises density, high unemployment, economic decline associated to a trend of emigration to other states, mainly to United States, and cities far away, with the consequent abandonment of agricultural land and the deterioration of the natural habitat.

Since 1980, Mexicans have been the largest immigrant group in the United States. In 2013, approximately 11.6 million Mexican immigrants resided in the United States (up from 2.2 million in 1980) and they accounted for the $28 \%$ of the country's foreign born ( 41.3 million). This situation generates a radical change in lifestyles, food consumption, and a loss in material culture, because people try to emulate other cultures losing totally their own local culture and traditional know-how. In recent years, few farmers seek to improve the quality of life and well-being returning to cultivate the land in their own hometown. The population of this rural area, rather isolated, reveals to be intimately and intensely linked to the territory and to have a strong sense of belonging and aggregation. In addition, the farmers of the cooperative 
Ahuehuetla, with which we have been working, are very motivated for a substantial changing towards sustainable rural development.

The Ahuacuotzingo community was characterized by the production of panela, a sugarcane product obtained by boiling and evaporation the sugarcane juice unrefined. Land next to Ahuacuotzingo, now mostly abandoned or underutilized, was intended primarily for this crop and most of the people worked in this sector. With the advent of liberal market, a large quantity of white sugar produced in the United States and other countries, arrived in Mexico. This caused the sudden lowering of the price of white sugar and, consequently, a decrease in demand for panela that, by then, had become much more expensive.

Understand how the migration of humans out of rural areas affects those left behind is very important from a social and economic welfare point of view. At migrant destinations, immigrant labour enters into local production activities, complementing some factors while possibly competing with others (including some types of non-immigrant labour). It influences both the level and distribution of income in migranthost economies. The micro impacts of migration on agricultural productivity are complex. Rozelle, Taylor and deBrauw (1999), using simultaneous-equation methods and a data set from China, found that the loss of labour to migration significantly reduced grain yields, reflecting an absence of on-farm labour markets. One of the most important factors that must be considerated in order to investigate the migration impacts, both at migrant origins and destinations, is remittance.

The phenomena of migration, which for decades has driven masses of people from Mexican rural areas to US metropolis, is very complex. It has impact and consequences in the short, medium and long term, and affects the economic, social, cultural as well as environmental. The most pessimistic studies on migrationdevelopment interactions in source areas appeared in the 1970s and 1980s. A more optimistic scenario comes out from the researches on this topic in the 1990s. If we want to find the true impact of migration we have to position ourselves in the middle, between these two ways of thinking. In recent years studies about migration suggest that the interaction between migration and key economic variables represents a complex combination of these two ideas. For example, recent studies find that migration has both negative "lost-labour" and positive remittance effects on source economies. In the United States, new research indicates that the impacts of immigration are complex, operating through indirect channels largely ignored by past research. New research methods generally are required to uncover interactions between migration and economic changes at migrant origins and destinations.

Furthermore, we have considered the issue of food security and climate change. Rural areas are characterized by a very strong specificity, social and environmental. It is necessary therefore to investigate these aspects to better understand the strengths and potential of the territory in order to promote the "revitalization".

\subsection{A real "security crisis" in the State of Guerrero.}

Insecurity and violence associated with organized criminal activity are pervasive in Mexico's southern state of Guerrero. The state's homicide rate is the highest in the country and extortion and kidnapping are commonplace. The state is divided into territories within which either drug trafficking organizations (DTOs) or community policing networks exercise control over local policing functions. What happens in rural areas is that competition between groups of traffickers over the state's prodigious narcotics output creates violent no-man's-lands in buffer zones between territories controlled by rival groups. The single most important source of DTO earnings are profits from the sale of heroin derived from poppy that is grown in the mountains throughout the state. An estimated sixty per cent of Mexico's poppy crop is grown in Guerrero. State efforts to suppress the violence and the associated criminal activities have been disorganized and have not been successful. Part of the problem clearly involves the permeation of state 
institutions by DTOs. A substantial portion of the state's population depends on earnings derived from narcotics production and many others depend on revenue streams that involve DTO participation. Reducing the economic role of DTOs will cause substantial dislocation and hardship that the state and federal governments must be prepared to address.

In a communiqué published at the beginning of May 2015, the Tlachinollan Mountain Center for Human Rights warned that the "violence has no limits, and the lack of capacity of the authorities to confront it is evident. The political class finds itself trapped within its own labyrinth. It fell into the same claws of the crow that gave birth to it, and it has had to submit itself to the very laws of barbarism which it has itself imposed. Guerrero is a territory mined by violence. There is no place there that escapes control by organized crime [...]. "

In 2014, the murder rate in the State of Guerrero was the highest in Mexico and eight times the national average. It was the year that 43 students from the Ayotzinapa rural teachers' college were taken into police custody in the town of Iguala and disappeared. A search expedition did not locate the missing students, but uncovered hundreds of hidden graves of unidentified human remains buried in the gloomy hills outside the town. The murder rate so far in 2015 is 29 percent higher compared to the same period a year ago.

\subsection{The contrast place}

The rural area of Ahuacuotzingo is characterised by strong and deeply rooted contrasts. This mainly caused by the fact that it is a territory in many ways underdeveloped but which suffered the consequences of globalization. Many inhabitants of Ahuacuotzingo have televisions, someone have mobile phones, few people the internet connection. This is substantially the cause of the larger part of the contrasts.

The analysis done through literature review on rural development and social innovation in rural development and the investigation on Ahuacuotzingo community reveals us the main territorial strengths and weaknesses.

The rural area is fragile and rich at the same time. Weak and strong at the same time. Stable, planted in the area, connected to the environment, aware depending upon it. It's an isolated and distant place from the rest of the world, but very strongly connected to the territory. The reason of contrasts, contradictions and paradoxes lies in the feeling of mexicanidad described by Octavio Paz and Carlos Fuentes in their literary work. This emotion is expressed primarily as a deep love for the roots which lives together with an ever-present sense of loss and regret mixed to a sense of pride for the cultural heritage. The portrait that emerges is of a population constantly looking for itself, or rather, for a clear identity. A people in whose veins run two legacies: the indigenous one and Spanish one. The Spanish heritage, for obvious reasons, is a baggage that is experienced by the Mexicans in a contradictory and indefinite way.

\section{Systemic design project}

The research provides an example of how to create well being and an important economic flow applying the SDA in Ahuacuotzingo context. From the focus on the product the attention moves to flows that generate different activities.

The system project begins with the definition of priorities: first define the actors, than their activities, al last design the material and energy flow. We initially identified the main actors, that is the members of the Cooperative Ahuehuetla, born thanks to this project. The main actors are: 5 farmers (Nacho, Tonio, Josè, Angel and the Cavideco-Centro de Apoyo para el Desarrollo y Vinculación Comunitario, Beto) 
holding a total of 43 hectares, but currently cultivating only 12 hectares, 1 group of women that cultivate a greenhouse for the production of organic vegetables, 1 group of women, sisters, who have recovered the activity of production of panela which had been abandoned by their father. The actors of the system work as if they were part of the same organism. Each farmer or actor becomes specialized in one activity in particular. The waste of each activity are used and returned in other productive activities. This allows the generation of new products, which do not exist at the moment. Nacho is the farmer who recently became part of the Ahuehuetla Cooperative. His role in the project is important as a producer of fish. For his breeding he uses worms arising from the production of Tonio. Tonio, which is at the moment the farmer better organized and with the best production, in the project produces sugar cane, which is useful for the feeding of animals but, above all, is brought to the group of women for the production of panela and derivatives. Thanks to the biodigester he produces biogas used in his tortilleria. In this activity he uses the corn that he produces on his field. His other productions are butter, cheese and yogurt, worms, compost, agave. The main activity of Beto is instead the dairy where he produces cheese, butter and yogurt. These products can be partially sold and partially used at the Cavideco. Jose produces sugar cane, corn and nopales. It has a small breeding whose products sells directly on the production site. Angel is the operator of the Cavideco that was founded in 2009. This centre was founded with the objective of developing the skills of men and women respecting environmental sustainability, promoting a natural tourism project and volunteering using local resources for the community development. This centre is one of the key locations for the project. It's a meeting point for cooperative members, here there is the restaurant and the natural swimming pool for the whole community, there are laboratories for the transformation of the food produced by the farmers of the cooperative. Furthermore it's the place where workshops and seminars will be are. An important part of the project provides that the Cavideco will become an essential place to develop the potential of the community. Here indeed practical workshops will be organized for the farmers and for the whole community of Ahuacuotzingo. Seminars and workshops will be organized primarily to support the farmers and other workers of the community in its activities. This part of the project relating to the education and organization of these courses is a practical outcome that we have already achieved. Inside the event Verano Intercultural courses were held to educate farmers in relation to self-construction of micro bio digesters and greenhouses for vermicomposting. Essential activities in the system project. Cavideco will also be the point of contact, the link between the Ahuahuetla Cooperative and the rest of the community. Here indeed it will be possible to purchase the products of the cooperative that will become the main results of a virtuous production system that uses in the best way possible the resources of the area and considers the output of the system, not as waste, but as an important input for other productive activities. New producs outcome from the Systemic Design project applied to Ahuehuetla Cooperative. 


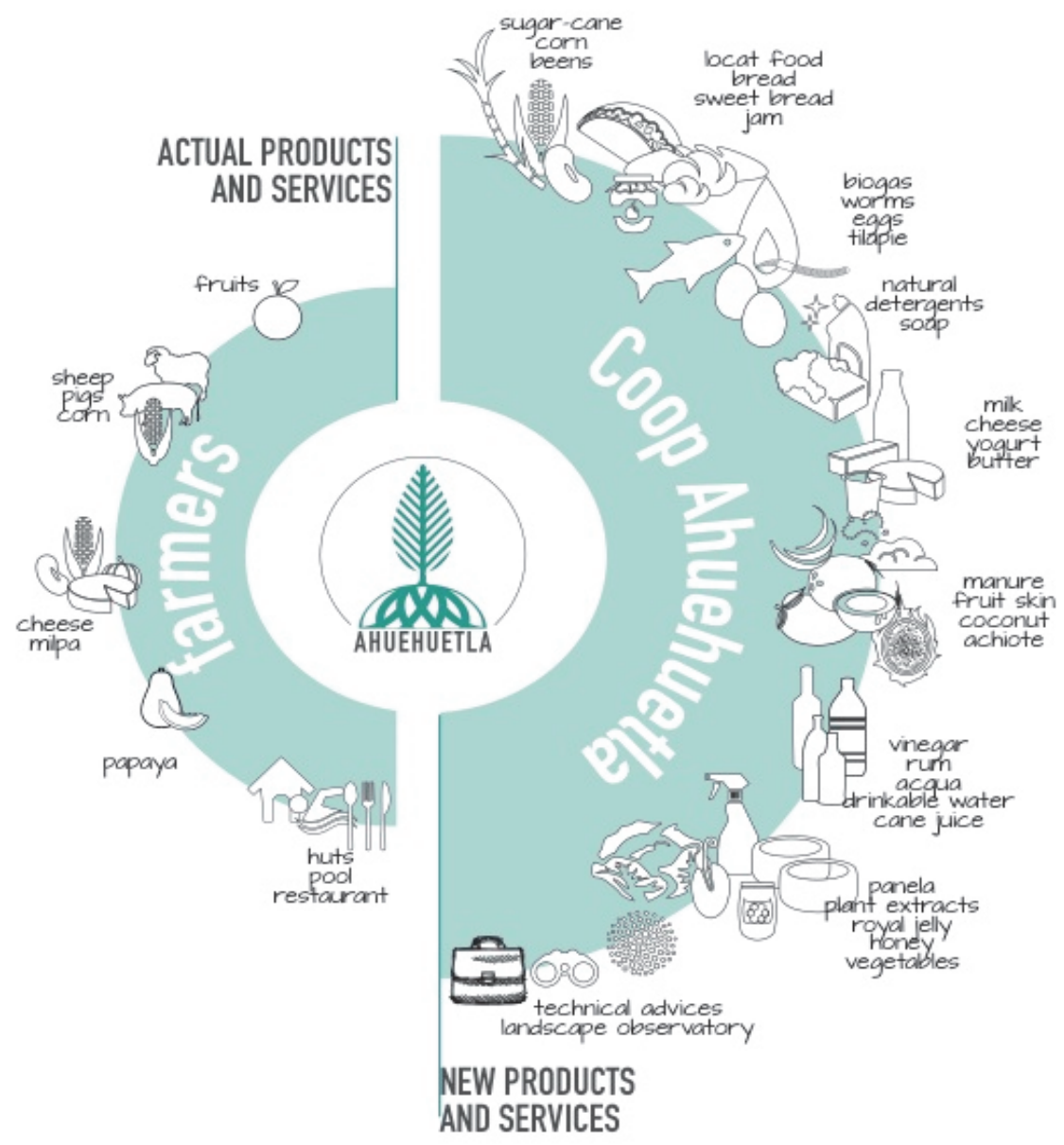

Fig. 2 New products by the Cooperative Ahuehuetla throwth the application of Design Systemic Approach

\section{Main results}

The conversion of the waste of the area into resources generates many new products and related production activities, such as fish farming, compost and worm compost, worm farming, seeds selfproduction, natural filtering of water, biogas, bio detergents and natural soaps, panela (which was the typical and most important production of this area until it has been replaced by the refined white sugar), honey. We have divided the main results in Preliminary Results and Outcomes.

Preliminary Results are practical results, already achieved during these years of research. First of all the creation of the Ahuehuetla Cooperative, which is the first step of the project, to involve people in the research. Within the project of Ahuehuetla Cooperative, we also dealt with the design of the logo, which is the central visual element that helps to identify and remember the brand. As happen in every company, this icon is a real symbol: the main purpose of it is to summarize and underline shared concepts and values from farmers. It is not only a graphic action, a graphic sign but it is a way to define and promote a strong and precisely identity for the farmers and the entire community. Other fundamental preliminary results are the improvements made in 2015 at the Cavideco. Two biodigesters were built, in which is disposed organic waste and that generates biogas that is used in the kitchen restaurant. Kitchens chimneys were equipped, a small improvement but very important considering the diffusion of respiratory diseases 
Rural development and sustainable innovation. How Systemic Design approach can contribute to the growth of marginal regions.

caused by the production of smoke in the kitchens. Further more we have planted at the Cavideco 40 fruit trees, for the production of oranges, lemons, mangoes, bananas that are used directly in the restaurant or processed in the laboratory. It was built with discarded materials, an entertainment area for children who attend the centre. The sheet metal on the roof has been replaced with a structure waterproofed using a fabric covered with a natural substance derived from the viscous liquid which is obtained from nopal, a typical and widely present plant in the territory. Furthermore, a greenhouse for the production of vermicomposting has been built.

Outcomes are above all regarding the implementation of the project. The Outcomes are the key research results, in line with the objectives set at the beginning of the project. First of all the framework, useful for other rural development projects in similar contexts, than the definition of the steps for the implementation of the project, the definition of active actors team in all phases of the Approach of DS application process.

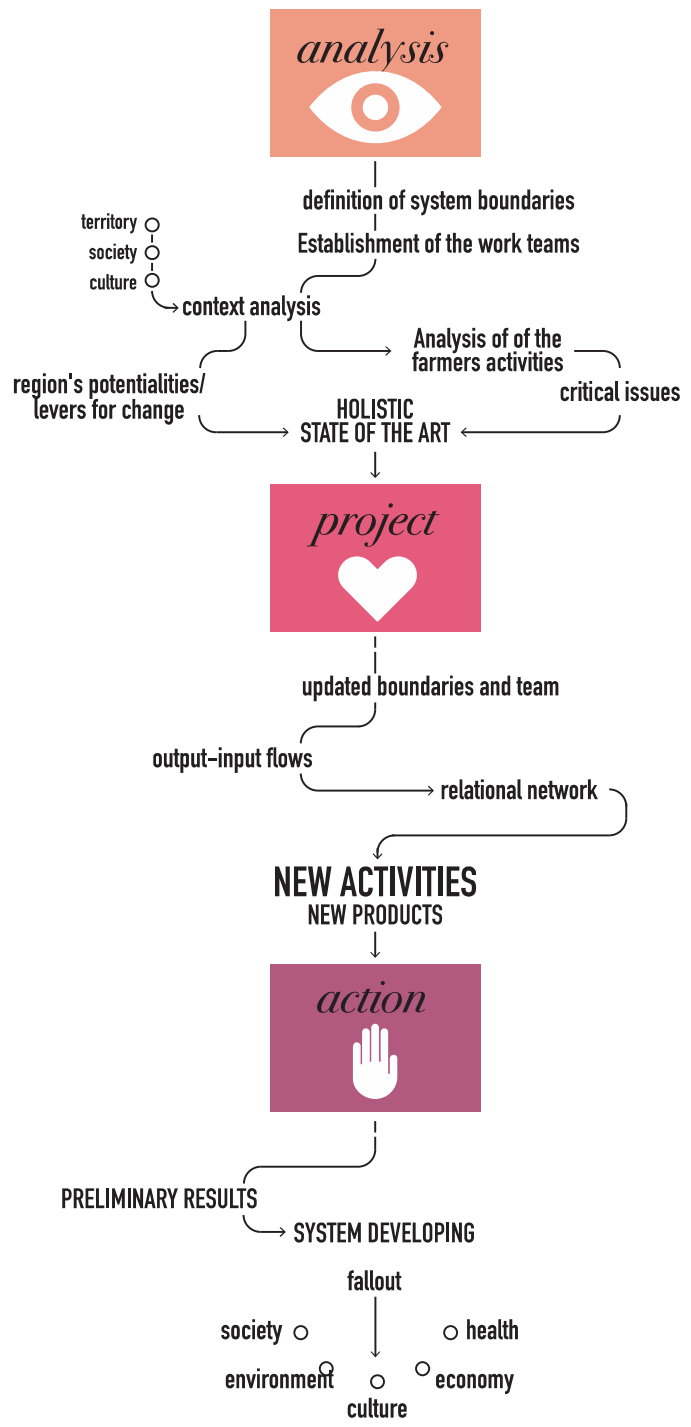

Fig.3 Framework for rural development applying Design Systemic Approach 


\section{Conclusion}

Expected results regard social, economic, environmental and health aspects. The farmers of the cooperative Ahuehuetla can become not only self-sufficient in terms of energy and food production, improving the quality of life, but also increasing the supply of food products, both unprocessed and processed.

During the Field research some important needs from the farmers came up: for example, they need to have counseling and contacts with experts and technicians in the field of organic farming and appropriate technology. This is why we designed and managed also the educational part of the project, mainly divided into two parts. On one side, some practical courses held by technicians and addressed to farmers already have been organised in Ahuacuotzingo at Cavideco. On the other side, Systemic Design seminars addressed primarily to university students can be organized, with the purpose of developing the competences in designing and organizing flows in a system. This is the reason why we are working together with Nuria Costa Leonardo, one of the 1000 women proposed for the Nobel Peace Price 2005, involved in different projects with the Red Mexicana de Mujeres (rememur) on socially responsible business related to rural development. This also helps us to relate to a distant reality from ours, though often so similar to many other rural areas all around the world. A very important result is the definition of pathways and frameworks that lies under the systemic project. This is what makes it scalable and replicable. The starting data, defined during the preliminary phases of analysis of the Holistic State of the Art, are subject to different variations. It depends on many factors, especially as the impossibility of farmers themselves to quantify their own inputs and outputs. This limit turns out to be insignificant precisely because the main objective is not the quantitative result, but the identification of a framework that can be reused and exported to other rural realities in order to foster sustainable development.

\section{References}

AA. VV. (2005), World Development Report 2005. A Better Investment Climate for Everyone, The World Bank, Oxford University Press: New York, [See: 02/10/2014]

$<$ http://siteresources.worldbank.org/INTWDR2005/Resources/ complete_report.pdf $>$

AA. VV. (2011), Rural Poverty Report, International Fund for Agricultural Development (IFAD), Roma <www.ifad.org/documents/10180/c47f2607-3fb9-4736-8e6a- a7ccf3dc7c5b.> [See: 11/06/2015]

ADAMS, D., HESS M. (2008). "Social innovation as a new public administration strategy". Proceedings of the 12th annual conference of the International Research Society for Public Management. Brisbane, pp. 1-8. 2008

BRUNORI G., RAND S., PROOST J., BARJOLLE D., GRANBERG L., DOCKES A.C. (2008), Towards a Conceptual Framework for Agricultural and Rural Innovation Policies, Frankfurt: In-Sight Project.

CHAMBERS, R. (1983) Rural development: putting the last first. Harlow: Prentice Hall.

CONDE C., FERRER R., OROZCO S. (2003), Adaptation to Climatic Variability and Change in Tlaxcala, Mexico, Climate Change, Adaptive Capacity and Development, Imperial College Press: London. [See: 07/06/2015]

GIBSON C.J., LENNON E. (1999), Historical Census Statistics on the Foreign-born Population of the United States: 1850-1990, Population Division, U.S. Bureau of the Census: Washington. $<$ http://www.census.gov/population/www/documentation/twps0029/twps0029.html>. [See: 03/12/2015]

LÉLÉ, S.M. (1991), "Sustainable Development: A Critical Review” in World Development, vol. 19, n. 6, giugno 1991.

MCINTYRE B.D., HERREN H.R., WAKHUNGU J., WATSON R.T. (2009), Agriculture at a Crossroads: International Assessment of Agricultural Knowledge, Science and Technology for Development (IAASTD). Global 
Rural development and sustainable innovation. How Systemic Design approach can contribute to the growth of marginal regions.

Report, Island Press, Washington, DC (USA) <www.unep.org/dewa/agassessment/reports/IAASTD/EN/ Agriculture\%20at\%20a\%20Crossroads_Global\%20Report\%20(English).pdf $>$ [See: 13/02/2015]

MURRAY R., CAULIER-GRICE J., MULGAN G. (2010), The Open Book of Social Innovation, London: The Young Foundation. <www.nesta.org.uk/sites/default/files/the_open_book_of_social_ innovation.pdf.> [See: 13/12/2014]

NEUMEIER S. (2012), "Why Do Social Innovations in Rural Development Matter and Should They Be Considered More Seriously in Rural Development Research? - Proposal for a Stronger Focus on Social Innovations in Rural Development Research" in Sociologia Ruralis, European Society for Rural Sociology, vol. 52, n. 1. $<$ http://onlinelibrary.wiley.com/doi/10.1111/j.1467-9523.2011.00553.x/abstract> [See:25/03/2015]

ROSADO J.L., LOPEZ P., MORALES M., MUNOZ E., ALLEN L.H., "Bioavailability of Energy, Nitrogen, Fat, Zinc, Iron and Calcium from Rural and Urban Mexican Diets” in British Journal of Nutrition, vol. 68, n. 1.

ROSADO J.L., LÓPEZ P., MORALES M., MUNOZ E., ALLEN LH. (1992), "Bioavailability of Energy, Nitrogen, Fat, Zinc, Iron and Calcium from Rural and Urban Mexican Diets”, in British Journal of Nutrition, vol. 68, n. 1.

S. ROZELLE, J.E. TAYLOR, A. DE BRAUW (1999), "Migration, Remittances, and Agricultural Productivity" in China, in The American Economic Review, vol. 89, n. 2. <https://www.aeaweb.org/articles?id=10.1257/aer.89.2.287> [See: 03/05/2015]

STAMOULIS K.G. (2001), Food, Agricolture and Rural Development. Current and Emerging Issues for Economic Analisys and Policy Research, Roma: Economic and Social Department of Food and Agriculture Organization of the United Nations (FAO). <www.fao.org/docrep/003/x9808e/x9808e00.html.> [See 02/05/2015]

VAN DER PLOEG J. D., BOUMA J., RIP A., RIJKENBERG F.H.J., VENTURA F., WISKERKE J.S.C. (2004), "On Regimes, Novelties and Co-Production" in Seeds of Transition: Essays on novelty production, niches ans regimes in agriculture, Assen (NL): Van Gorcum <http://www.wageningenur.nl/en/Publicationdetails.htm?publicationId=publication-way-333238353538> [See 29/07/2015]

VAN DER PLOEG J.D., BOUMA J., RIP A., RIJKENBERG F.H.J., VENTURA F., WISKERKE J.S.C., On Regimes, Novelties and Co-Production, cit. Censo de Población y Vivienda 2010, Instituto Nacional de Estadística y Geografía (INEGI) <www.inegi.org.mx/est/contenidos/proyectos/ccpv/cpv2010/ default.aspx.> [See:25/03/2015]

WATERS T. (2007), The Persistence of Subsistence Agriculture: life beneath the level of the marketplace, Lanham: Lexington Books. 